\title{
Carbon Footprint and Life Cycle Assessment of PET Bottle Manufacturing Process
}

\author{
Salman Alfarisi ${ }^{1}$, Rangga Primadasa ${ }^{2}$ \\ \{salman.alfarisi@umk.ac.id ${ }^{1}$, rangga.primadasa@umk.ac.id $\left.{ }^{2}\right\}$
}

Departement of Industrial Engineering, Faculty of Engineering, Universitas Muria Kudus ${ }^{12}$

\begin{abstract}
The use of plastics is increasing in modern society. The data shows that packaging is the highet consumer of plastic. Bottle grade PET is one of the most important of plastic packaging. The purposes of this research is to analyze the carbon footprint and the impact contribution of PET bottle water. Life cycle assessment (LCA) approach was used as guidelines framework and life cycle impact assessment (LCIA) was used to find out the impact of PET bottle water. Electricity has the highest contibution to carbon dioxide emission quantity 1.089E $3 \mathrm{~m} 2 \mathrm{a}$. The three highest impact of PET bottle water manufacturing process were global warming quantity $650.1 \mathrm{~kg} \mathrm{CO} 2$ eq, human toxicity quantity $267 \mathrm{~kg}$ 1,4-DB eq and marine aquatic ecotoxicity quantity 16 $\mathrm{kg}$ 1,4-DB eq. Then, the scenario of sustainability must be implemented on the production of PET water bottle for decreasing the threat of conventional PET bottle water production.
\end{abstract}

Keywords: carbon footprint, polyethylene terephthalate (PET), life cycle assessment (LCA), global warming, human toxicity.

\section{Introduction}

The use of plastics is increasing in modern society. Unique features of plastics, such as lighweight, durable, and more cost-effective materials with respect to many others, which make them highly competitive in the market [1]. Plastic is used in a wide range of application sectors, such as packaging, building and construction, automotive and aeronautics, electrical and electronic equipment, agriculture, leisure and sport equipment or medical and health product [2]. Indonesia as the 4th most populous counttry globally, has the high demand of plastics. But, local plastic industries rely on import because of the shortages of raw material. It is about $40 \%$ of petrochemicals used in the plastics industry comes from neighboring country, such as Singapore, Malaysia and Thailand, as well as from Europe, US and Middle East [3]. The plastics demand in Indonesia is dominated by packaging sector $(55 \%)$ followed by other sector as shown in figure 1.

The data shows that packaging is the highet consumer of plastic. The plastic demand in Indonesia will continue to increase because the consumption is always growing. Poliethylene terephthalate (PET) is a plastic material which has found increasing application in the production of packaging [4]. Bottle grade PET is one of the most important of plastic packaging. PET has a rapid grow of consumption. In 2007, the worldwide consumption of bottle grade PET in 2007 was 15 million metric tonnes $\left(10^{6} \mathrm{Mt}\right)$ [5]. Bottled water consumption is reaching a high record in 2015 with 11.7 billion gallons [6]. As industry

ICCSET 2018, October 25-26, Kudus, Indonesia

Copyright (C) 2018 EAI

DOI 10.4108/eai.24-10-2018.2280596 
booms, however, it also leads to over resources use, human health, and greater impact to ecological systems [7].

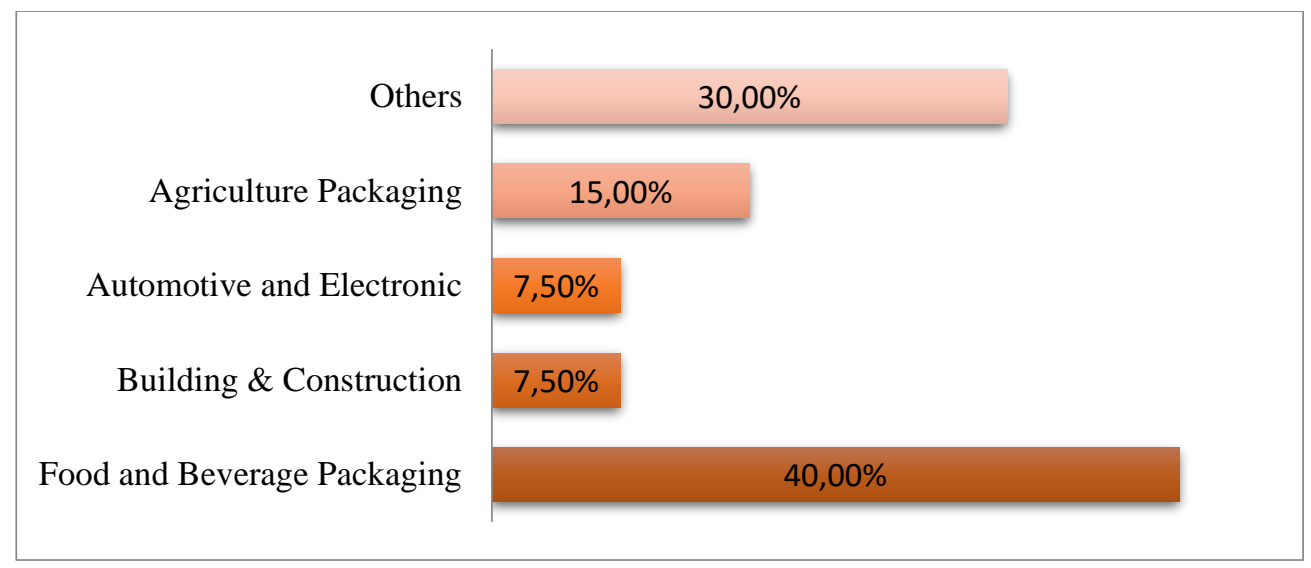

Fig. 1. Distribution of Indonesian Plastics Demand by Segment in 2015 (source: BPF Report, 2015)

PET is a long-chain polymer whisch is part of polyester family [8]. PET bottle are a threat to environment due to the high amount of chemical material required in production process, as well as incorrect usage and disposal of product [9]. Based on the research that have been conducted by Center for Sustainable Systems, University of Michigan in 2015, approximately 7.2-14.1 million tons of plastic waste disposed of in landfills and it is contribute for $22 \%$ $43 \%$ of waste disposed in landfills [10]. The problem of this waste is the majority of this plastics are not biodegradable, and the bulk of this will persist for decade or centuries [11]. Today, the awareness of the potential damages of plastics is arisen, both in production process and disposal product.

The Primary purposes of this research is to analyze the carbon footprint and the impact contribution of PET not only to ecological systems, but alse the impact on human health. The carbon footprint has widely used to show the certain amount of gasseous emission that relevant to climate change [12]. The ecological system of this research including global warming, marine water aquatic ecotoxicity. Life cycle assessment (LCA) approach is used to find out the impact of this product because LCA is powerful approach to identify and analyse the impact of each materials [13]. The result of this research will be used to develop alternative solution on the next study to prevent or reduce the PET impact to ecological systems and human health.

\section{Methodology}

The framework of this research is following LCA framework which has been standardised by ISO 14040 . 


\subsection{Goal and system boundary}

The goal of this reasearch is to assess and analyse the PET impact to ecological systems and human health. The PET on this research is specified on bottled water. The material of PET used is PET of bottle grade and Polyethilene High Density (PE-HD). The system boundary of bottled water product is cradle to gate. The beginning of this boundary is material manufacturing to end process of bottle production. This boundary was used to focus on PET impact of production process. In previous research, some scholar has included the distribution proces, water filling, and other activity on their research. But, inputing those activity will make the result bias if the focus of research is to find out and analyze the impact of PET. The simulation of the impact assessment on this research by using openLCA software.

\subsection{Life cycle Inventory}

Life cycle inventory was established from the input of product. The model graph of material input shown in figure 2. The reference used of the product is number of items. The database od material used was based on European Commission (ELCD 3.2 GreenDelta V2.17). Life cycle impact assessment (LCIA Method 1.5.7) database was used to evaluate and analyse the impact assessement of PET on production process. The calculation of impact assessment method was based on CML 2001 (all impact categories). Normalization an weighting set used in this research is World. 1995 - CML 2001 (all impact categories).

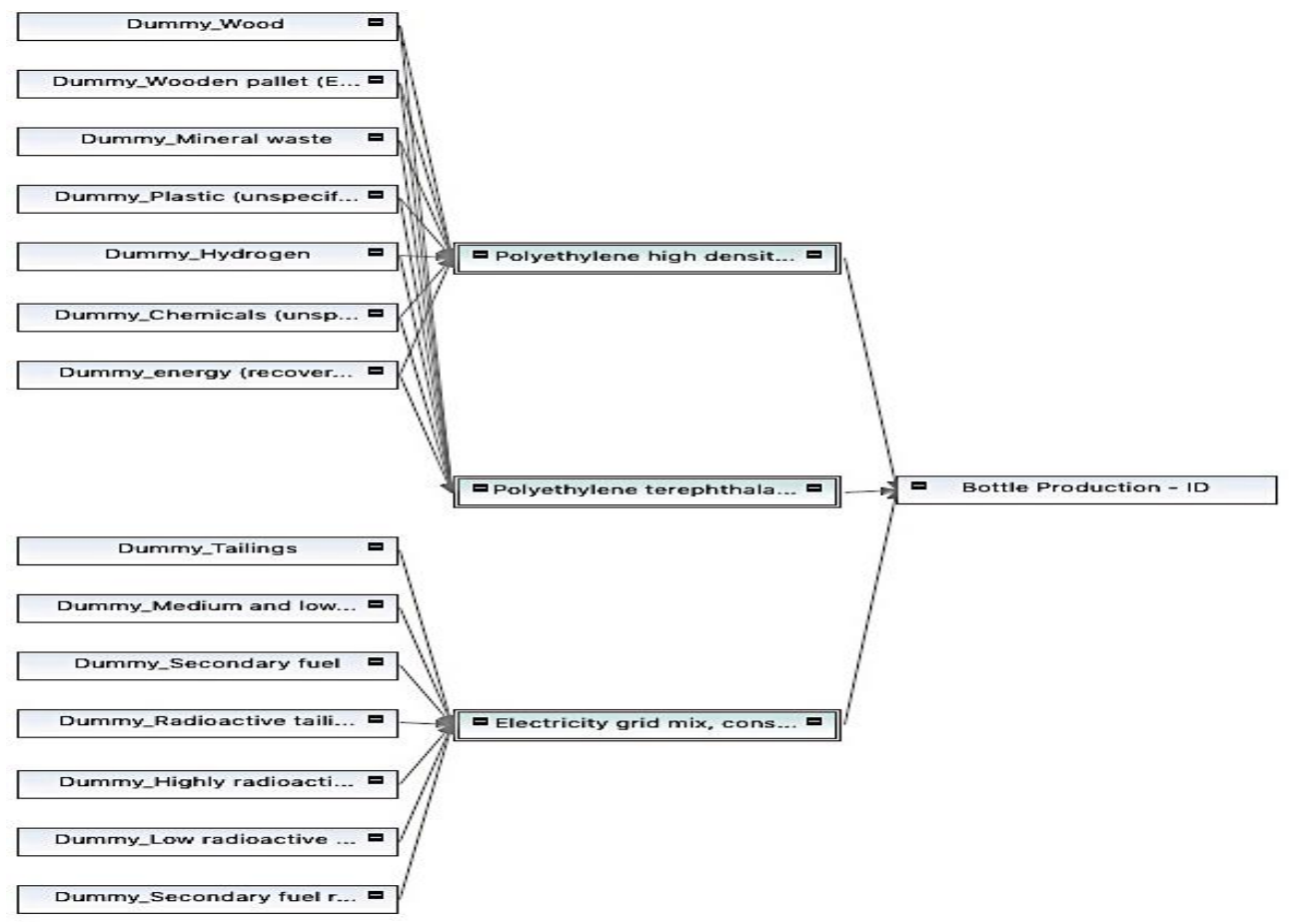

Fig. 2. Model Graph of Material Input on Bottle Water Production Process. 


\section{Result and Discussion}

\subsection{Input and output of material}

Input of material is the quantitative value of the origin material that needed in production process. Actually, the input of material is the breakdown of model graph of material input, but the input of material as shown in table 1 is more specific which is containing the category, sub-category, unit, and amount.. The scenario of this research is to produce 1000 bottle water. So, the input of material in table 1 was set as the scenario.

Table 1. Material input of PET material in manufacturing process.

\begin{tabular}{lllll}
\hline Materials & Category & Sub-category & Reference Unit & Amount \\
\hline Nitrogen & Resource & in air & $\mathrm{kg}$ & 19.46618802 \\
Barite & Resource & in ground & $\mathrm{kg}$ & $7.33033 \mathrm{E}-06$ \\
Basalt & Resource & in ground & $\mathrm{kg}$ & $1.55438 \mathrm{E}-05$ \\
Bauxite & Resource & in ground & $\mathrm{kg}$ & 0.001146828 \\
Brown coal & Resource & in ground & $\mathrm{MJ}$ & 3728.333521 \\
$\cdot$ &. &. &. &. \\
$\cdot$ &. &. &. \\
Calcium carbonate & Resource & in ground & $\mathrm{kg}$ &. \\
Calcium chloride & Resource & in ground & $\mathrm{kg}$ & 13.22182944 \\
Chromium & Resource & in ground & $\mathrm{kg}$ & $3.70497 \mathrm{E}-11$ \\
Tantalum & Resource & in ground & $\mathrm{kg}$ & 0.00244882 \\
Tin & Resource & in ground & $\mathrm{kg}$ & 0.000559168 \\
Titanium & Resource & in ground & $\mathrm{kg}$ & $9.93042 \mathrm{E}-10$ \\
Uranium & Resource & in ground & $\mathrm{MJ}$ & $2.14635 \mathrm{E}-06$ \\
\hline
\end{tabular}

\subsection{Carbon Footprint}

Carbon footprint on this reaserch was a common baseline to show amount of carbon dioxide emitted by manufacturing process of PET. The quantify of carbon footprint was measured by using ecological footprint calculation (see fig.3). Electricity has the highest contribution to carbon released with the quantity $1.089 \mathrm{E} 3 \mathrm{~m}^{2} \mathrm{a}$, then followed by PET granulate bottle grade and polyethylene high density (PE-HD) with values $4.686 \mathrm{E} 2$ and $20.934 \mathrm{~m}^{2} \mathrm{a}$. The consumption of electricity during manufacturing process affected the carbon released to the atmosphere and affected to global warming potential

\subsection{Environmental impact of PET bottle water}

Environmental impact of PET bottle water was assessed by using life cycle impact assessment (LCIA). After building the model graph and specific input to create product system, then the calculation of impact assessment can be conducted. By using CML 2001 (all impact categories, found three highest impact of PET bottle water production process, these are global warming, human toxicity and marine aquatic ecotoxicity (see table 2). 


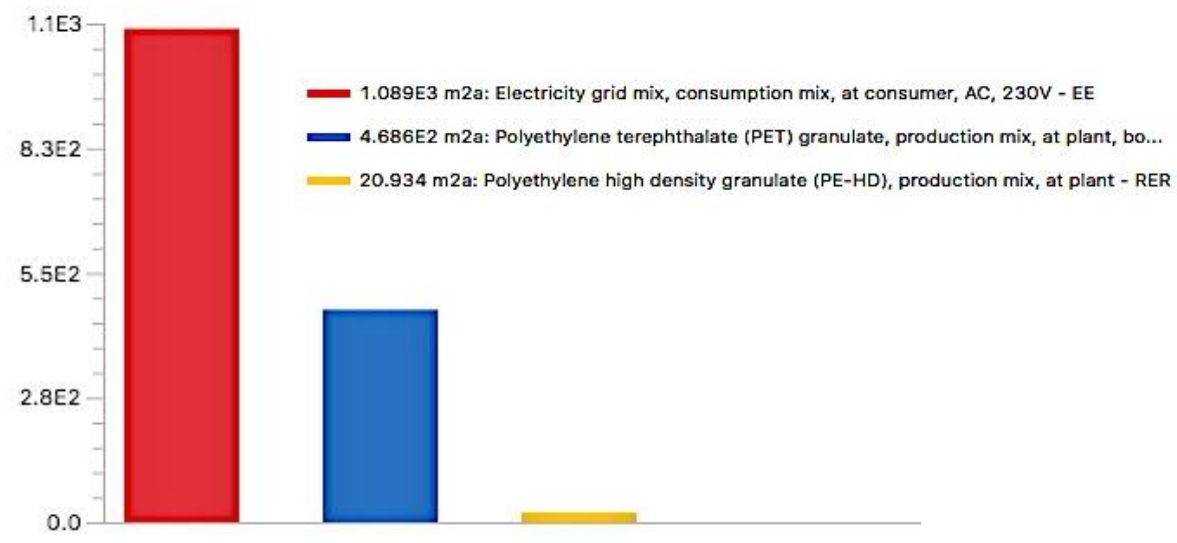

Fig. 3. Carbon emission of PET manufacturing process

Table 2. Impact assessment of PET in manufacturing process stage.

\begin{tabular}{lll}
\hline Impact Categories & Value & Reference Unit \\
\hline Human toxicity 100a - CML 2001 (all impact categories) & 267.0 & $\mathrm{~kg} \mathrm{1,4-DB} \mathrm{eq}$ \\
Marine aquatic ecotox. 100a - CML 2001 (all impact categories) & 16.0 & $\mathrm{~kg} \mathrm{1,4-DB}$ eq \\
Global warming 100a - CML 2001 (all impact categories) & 650.1 & $\mathrm{~kg} \mathrm{CO}_{2}$ eq \\
\hline
\end{tabular}

Based on the impact assessment calculation of PET on manufacturing process, It was found that the PET manufacturing process contribute in 49 impact categories and the three highest of the impact is global warming 100a, human toxicity 100a and marine aquatic ecotoxicity 100a. The detail result of each impact categories shown in figure 3-5.

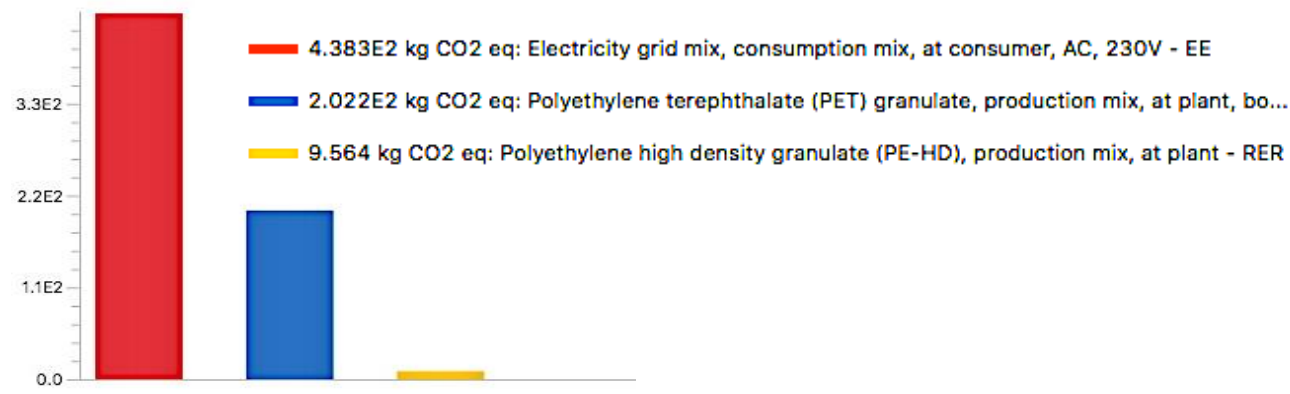

Fig. 4. Input materials contribution to global warming impact category.

Sankey diagram was the approach which is used to read the result of the input materials contribution to each impact categories. Global warming on this case refer to some substances released to environment and lead to greenhouse gases (GHGs) such as methane, carbon 
dioxide. Carbon dioxide, methane, and other substances can change the Earth's atmosphere and warm the planet. Based on fig. 3, the highest material that contibute to global warming impact category was electricity of production at plant that showed by red colour with quantity $4.383 \mathrm{E} 2 \mathrm{~kg} \mathrm{CO}_{2} \mathrm{Eq}$, then followed by PET granulate bottle grade and polyethylene high density (PE-HD) with values 2.022E2 and $9.564 \mathrm{~kg} \mathrm{CO}_{2}$ eq. Red colour in sankey diagram means the material has the highest contribution while blue colour means lower contribution to impact category.

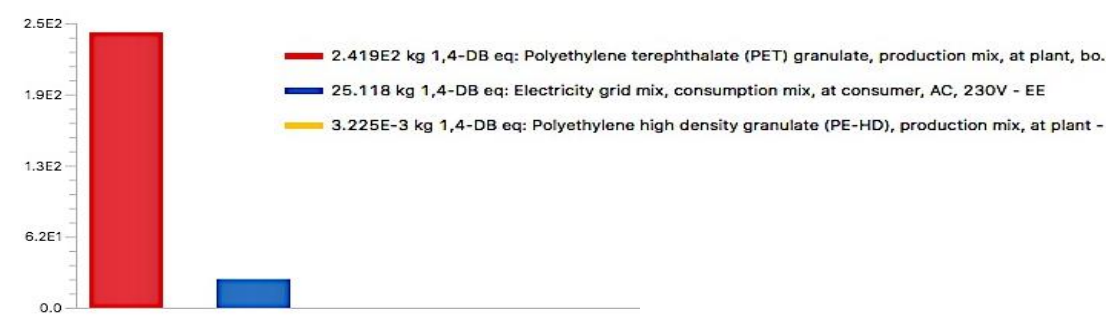

Fig. 5. Input materials contribution to human toxicity impact category.

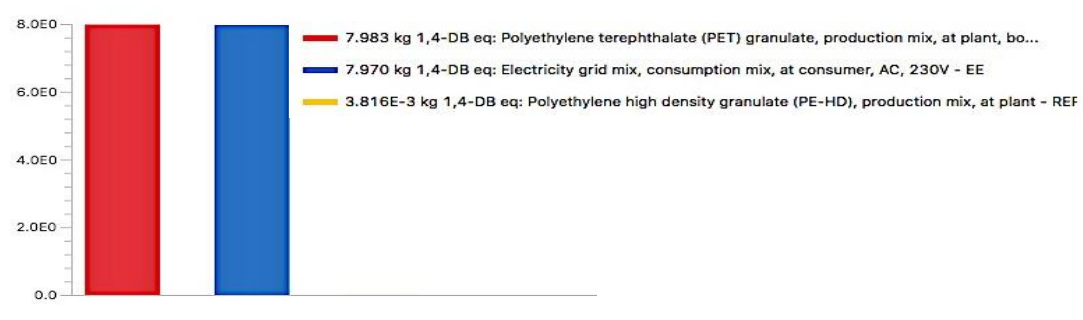

Fig. 6. Input materials contribution to marine aquatic ecotoxicity impact category.

Human Toxicity was cused by the emmission of substances released than impact to human health, such as heavy metal. The calculation of human toxicity ware based on the acceptable (tolerance) concentration of toxic in air, ground, and water that can contaminated human health. On human toxicity impact category (fig.4), PET was the highest material that contribute to this impact category with quantity $2.419 \mathrm{E} 2 \mathrm{~kg} 1,4-\mathrm{DB}$ eq, then followed by electricity and PE-HD with values 25.118 and 3.225E-3 kg 1,4-DB eq. PET has the highest contribustion because the input material of PET is containing some material such as chromium, mercury, potassium and other material that threat the human healt. Then the accumulation of those material cause emission to air as output.

Marine aquatic ecotoxicity means that poisonous (toxic) substances released into the environment. On the third impact categories (fig. 5), marine aquatic ecotoxicity, PET still the highest material that contribute to marine aquatic ecotoxicity, then followed closely by 
electricity with values 7.983 and $7.970 \mathrm{~kg}$ 1,4-DB eq. PE-HD is the lowest material that contribute to each impact categories with values $3.816 \mathrm{E}-3 \mathrm{~kg}$ 1,4-DB eq.

\section{Conclussion}

This study has analyzed the life cycle assement of PET bottle water with the cradle to gate scenario to determine the impact ot the PET bottle water. The calculation was only focus on manufacturing process to found the carbon footprint and specific result of PET bottle water impact to ecological systems and human health. The calculation of carboon footprint was used ecological footprint and LCIA was used CML 2001 baseline (all impact categories) and resulted 49 impact categories. Electricity was the highest input that contribute to carbon carbon dioxide emission with the quantity $1.089 \mathrm{E} 3 \mathrm{~m}^{2} \mathrm{a}$. Based on the LCIA calculation, there were three highest impact, global warming quantity $650.1 \mathrm{~kg} \mathrm{CO}_{2}$ eq, human toxicity quantity $267 \mathrm{~kg}$ 1,4-DB eq and marine aquatic ecotoxicity quantity $16 \mathrm{~kg}$ 1,4-DB eq.

The result of this research concluded that the emission of carbon dioxide released also increase the global warming protential, so PET bottle water was a threat for ecological systems and human health. PET bottle water was very important on packaging especially for beverages sector, however, the impact of PET water bottle to ecological system and human health was harmful if always produced conventionally and high number of items.

\section{References}

[1] G. Valentino, "Life Cycle Assessment of PET bottles: closed and open loop recycling in Denmark and Lombardy region," 2016.

[2] I. Mersiowsky, "PlasticsEurope Eco-profiles Indispensable Building Blocks for Highquality PEF Studies Eco-profiles are Building Blocks," 2014.

[3] British Plastics Federation, "Plastics Industry in Indonesia report 2015," p. 7, 2015.

[4] S. K. Dogan, "Life Cycle Assesment of Pet Bottle," Dokuz Eylul Univ., p. 61, 2008.

[5] S. Alfarisi, Azwirman, and T. E. Sabli, "The influence of intangible benefit towards market share of manufacturing company," Adv. Sci. Lett., vol. 23, no. 9, pp. 8470-8472, 2017.

[6] G. J. S. Rodwan, “U.S. and International Developments and Statistics,” p. 20, 2015.

[7] N. Horowitz, J. Frago, and D. Mu, "Life cycle assessment of bottled water: A case study of Green2O products," Waste Manag., vol. 76, pp. 734-743, 2018.

[8] V. Sinha, M. R. Patel, and J. V. Patel, "Pet waste management by chemical recycling: A review,” J. Polym. Environ., vol. 18, no. 1, pp. 8-25, 2010.

[9] Rm. Rathinam, Tr. Ku mar, Ms. Raman, A. Professor, and U. Student, "Reuse of Bottles for Wall Construction and Crafting," Int. J. Eng. Sci. Comput., vol. 7, no. 4, pp. 6693-6696, 2017.

[10] G. Gourmelon, “• Global plastic production _ Statistic.”

[11] J. Hopewell, R. Dvorak, and E. Kosior, "Plastics recycling: Challenges and opportunities," Philos. Trans. R. Soc. B Biol. Sci., vol. 364, no. 1526, pp. 2115-2126, 2009.

[12] T. Wiedmann and J. Minx, "A Definition of 'Carbon Footprint," Science (80-. )., vol. 1, no. 01, pp. 1-11, 2007. 
[13] S. Alfarisi, S. B. Sutono, and W. Sutopo, "Evaluate the use of tanning agent in leather industry using material flow analysis, life cycle assessment and fuzzy multi-attribute decision making (FMADM)," AIP Conf. Proc., vol. 1902, p. 020053, 2017. 